\title{
Evaluation of Fuel Quality, Throughput Rate and Energy Consumption During Non- Industrial Wood Chip Production with Three PTO Driven Chippers
}

\author{
Daniel Kuptz, Hans Hartmann
}

\begin{abstract}
Physical wood chip quality is essential for failure-free and low emission combustion in small-scale boilers $\leq 100 \mathrm{~kW}$. In Bavaria, these furnaces are often operated by farmers or private forest owners that produce their own fuels using small to medium sized PTO-driven chippers. As secondary fuel processing steps such as industrial screening are usually too expensive for private forest owners, the selection of suitable raw materials and process parameters to directly produce high quality fuels during chipping are deemed especially relevant for this user group. In the present study, three commonly used small-scale chippers $\leq 150 \mathrm{~kW}$, i. e. a drum, a spiral and a disc chipper where evaluated in terms of fuel quality, throughput rate and energy consumption during wood chip production. Chipping was done using stem wood of European beech and Norway spruce. Machine settings were the ones recommended by the chipper manufactures for the production of high quality fuels. Additional chipping variants included the use of different raw materials such as crown residues of European willow and varying machine settings including blunt knives, increasing spiral cut length, large screen mesh sizes or increased PTO speeds. Representive wood chip samples were taken after each trial and analysed in their physical fuel properties according to international standards for solid biofuels but also using a continuously measuring image analysis device to determine particle length and particle shape. For all three mobile chippers, wood chips with the particle size class "P31s « according to the revised ISO 17225-4:2021 could be produced when stem wood was used as assortment. Fine content of chips, i. e. particles $\leq 3.15 \mathrm{~mm}$, was lowest for the spiral chipper and increased for the drum and disc chipper, especially when blunt knives or narrow screen meshes were used for chipping. At the same time, blunt knives increased the particle shape factor (PSF) of the bulk materials indicating a rather broken particle surface structure compared to clean cut particles. Throughput rate decreased and energy consumption increased when fuels with small particle size were produced, e. g. when narrow screen meshes or narrow chipping spirals were applied. This trend was particularly pronounced when blunt knives were used for chipping due to grinding of the material. All three chippers could be recommended for the production of high quality fuels for small-scale boilers when suitable machine settings and raw materials are applied for chipping.
\end{abstract}

Keywords: wood chip quality, particle size distribution, particle shape, throughput rate, fuel consumption, ISO 17225-4, image analysis

\section{Introduction}

Fuel quality is essential for failure-free and low emission biomass combustion (Kaltschmitt et al. 2016). Especially small-scale wood chip boilers $<100 \mathrm{~kW}$ re- quire high and defined physical and chemical fuel properties such as low moisture content, low ash content and homogeneous particle shape (Schön et al. 2019, Zeng et al. 2019). In Bavaria, small-scale boilers are often 
applied in private households by farmers or private forest owners who produce their own fuels using stem wood or forest residues from their respective forests. In the private sector, chipping is often done using small to medium-sized, manually operated mobile chippers that are usually powered by the PTO (»power take-off «) of a conventional tractor. Within this chipper size class $(\leq 150 \mathrm{~kW})$, many different chipper models are applied such as drum, disc or spiral chippers, whereas for larger forest operations in Bavaria, mostly drum chippers (self-propelled or PTO-driven by a tractor) with a high engine power are used.

Suitable physical and chemical fuel properties for wood chip combustion are given by the fuel specifications within the current international standards for solid biofuels. In case of graded wood chips for the use in small to medium sized boilers, the recently revised ISO 17225-4:2021 applies. This standard includes four defined wood chip specifications A1, A2, B1 and B2, and it describes a set of threshold limits for fuel properties such as moisture content or particle size distribution. The latter is represented by three particle size classes »P16s«, »P31s« and »P45s « for the use in smallscale boilers with defined limits for the maximum amount of fines, i. e. particles $<3.15 \mathrm{~mm}$, but also for overlong particles or the maximum particle length. Other relevant fuel quality parameters for combustion include ash content, ash melting behaviour or the chemical composition of fuels. As a general rule, fuel requirements for wood chip quality increase with decreasing boiler size (Kaltschmitt et al. 2016).

The restriction of physical fuel properties such as particle size distribution is especially relevant for smallscale combustion. A high amount of fine particles might lead to clogging of screw conveyors (Rackl and Günthner 2016) but also to wood dust related problems during filling of storage rooms (Kaltschmitt et al. 2016) or to increased $\mathrm{CO}$ and dust emissions during combustion (Schön et al. 2019). A high share of overlong particles leads to problems with clogging of screw-conveyors or to bridging of fuels within storage rooms (Daugbjerg Jensen et al. 2004). Particles with a roughly broken surface structure, e. g. hog fuel, strongly increase fuel bridging tendencies (Hinterreiter et al. 2012).

Fuel quality of wood chips depends on many process parameters during production, e. g. on the selected raw materials, chipper types or on relevant machine settings such as knife sharpness, screen size or chipper output system (Eliasson et al. 2015, Kuptz and Hartmann 2015, Spinelli et al. 2011). The selection of unsuitable process parameters for fuel production or careless chipping operations at forest production sites lead to a distinct decrease in fuel quality. Secondary fuel processing steps such as artificial drying or mechanical screening might help to improve low fuel properties (Kuptz et al. 2019, Nati et al. 2015, Oveisi et al. 2018), but these methods are mostly available on the industrial scale and require additional costs and labour for fuel processing and transport. As a consequence, they are usually not applied by private forest owners during wood chip production. Other recommendations regarding fuel quality management might be more suitable for this user group such as the selection of a suitable small-scale chipper (including the recommended chipper fine tuning) to a given raw material.

Similar to fuel quality, fuel production efficiency might be optimised by easy measures (Spinelli et al. 2014, Spinelli et al. 2016). Throughput rate and fuel specific energy consumption of the chipping process, i. e. the consumption of litres of gasoline per loose cubic meter $\left(\mathrm{lm}^{3}\right)$ or per ton dry matter (odt), strongly depends on the raw material (Spinelli et al. 2011), chipper size (Bergström and Di Fulvio 2019, Spinelli et al. 2017), chipper type and on specific machine settings such as knife sharpness, screen size, cut length or discharge system (Eliasson et al. 2015, Facello et al. 2013a, Nati et al. 2014).

This study focusses on non-industrial wood chip production for the application of fuels in small-scale boilers. The aim was to evaluate three PTO-driven mobile chippers, i.e. a drum, a spiral and a disc chipper, that are commonly used by private forest owners. Recommended machine settings for the production of high quality fuels were applied. Evaluation focussed on whether the selected process parameters can be deemend sufficient for the required physical fuel quality for small boilers and on whether secondary fuel processing steps such as mechanical screening are still necessary. Chipping experiments were done at TFZ (Technology and Support Centre in the Centre of Excellence for Renewable Ressources, Straubing, Germany) applying two high quality raw materials, i. e. stem wood of European beech and Norway spruce. Further variants include different machine settings or raw materials to identify optimization potential in fuel production regarding fuel quality, throughput rate and energy consumption.

\section{Materials and Methods}

A total of 16 individual chipping trials were performed at the depot area of TFZ with varying chippers, machine settings and raw materials. During each trial, one batch of wood chips of approx. $8 \mathrm{~lm}^{3}$ (loose cubic meter, $n=1$ ) was produced using one of three PTO-driven chippers $<150 \mathrm{~kW}$, i. e. a Heizohack HM 
8400 drum chipper (Heizomat Gerätebau-Energiesysteme $\mathrm{GmbH}$ ), a Laimet HP 21 spiral chipper (Laitilan Metalli Laine Oy) and a Farmi CH 260 HF-2EL disc chipper (Farmi Forest Oy) (Fig. 1, Table 1).
Raw materials for chipping derived from stem wood of Norway spruce (Picea abies) and European beech (Fagus sylvatica), but also from crown material of European willow (Salix spp., only one chipping
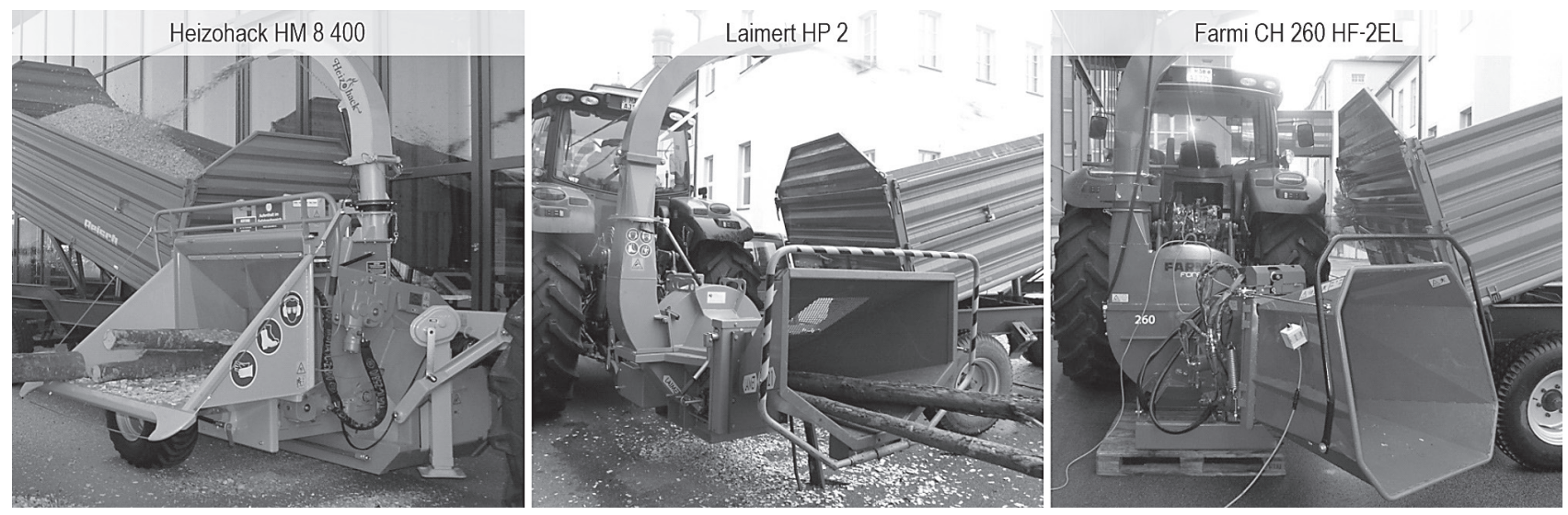

Fig. 1 Three PTO-driven chipper for the trials at TFZ

Table 1 Machine settings and raw materials used during 16 chipping trials with three PTO-driven chippers

\begin{tabular}{|c|c|c|c|c|c|c|c|c|c|c|}
\hline Chipper & $\begin{array}{l}\text { Power } \\
\text { demand }\end{array}$ & $\begin{array}{l}\text { Max. } \\
\text { infeed } \\
\text { diameter }\end{array}$ & Machine setting & $\begin{array}{c}\text { Tree } \\
\text { species }\end{array}$ & $\begin{array}{l}\text { No. of } \\
\text { stems }\end{array}$ & $\begin{array}{l}\text { Stem } \\
\text { length } \\
\mathrm{cm}\end{array}$ & $\begin{array}{c}\text { Stem } \\
\text { diameter } \\
\mathrm{cm}\end{array}$ & $\begin{array}{l}\text { Stem weight } \\
\mathrm{kg}\end{array}$ & $\begin{array}{c}\text { Total solid } \\
\text { volume } \\
\mathrm{m}^{3}\end{array}$ & $\begin{array}{c}\text { Total } \\
\text { weight } \\
\mathrm{t}\end{array}$ \\
\hline \multirow{6}{*}{$\begin{array}{l}\text { Heizohack } \\
\text { HM } 8400 \mathrm{~K}\end{array}$} & \multirow{6}{*}{$\max .139 \mathrm{~kW}$} & \multirow{6}{*}{$400 \mathrm{~mm}$} & \multirow{2}{*}{$\begin{array}{c}45 \times 60 \mathrm{~mm} \text { screen } \\
\text { sharp knives }\end{array}$} & $S$ & 37 & $297 \pm 13$ & $20.9 \pm 4.2$ & $71.1 \pm 27.5$ & 3.93 & 2.63 \\
\hline & & & & $\mathrm{B}$ & 33 & $401 \pm 18$ & $21.0 \pm 2.1$ & $143.1 \pm 29.2$ & 4.63 & 4.72 \\
\hline & & & $\begin{array}{c}60 \times 60 \mathrm{~mm} \text { screen } \\
\text { sharp knives }\end{array}$ & S & 41 & $300 \pm 18$ & $20.1 \pm 2.9$ & $67.8 \pm 20.2$ & 4.00 & 2.78 \\
\hline & & & \multirow{2}{*}{$\begin{array}{c}80 \times 80 \mathrm{~mm} \text { screen } \\
\text { sharp knives }\end{array}$} & $S$ & 35 & $298 \pm 11$ & $21.7 \pm 4.5$ & $80.8 \pm 33.1$ & 4.01 & 2.82 \\
\hline & & & & $B$ & 23 & $394 \pm 18$ & $20.3 \pm 1.4$ & $130.1 \pm 19.7$ & 2.95 & 2.99 \\
\hline & & & $\begin{array}{c}80 \times 80 \mathrm{~mm} \text { screen } \\
\text { blunt knives }\end{array}$ & $S$ & 42 & $297 \pm 11$ & $19.4 \pm 4.3$ & $66.1 \pm 30.9$ & 3.86 & 2.78 \\
\hline \multirow{5}{*}{$\begin{array}{l}\text { Laimet } \\
\text { HP } 21\end{array}$} & \multirow{5}{*}{$\begin{array}{l}75 \text { to } 110 \\
\mathrm{~kW}\end{array}$} & \multirow{5}{*}{$170 \mathrm{~mm}$} & \multirow{3}{*}{$\begin{array}{l}\text { spiral cutting length } \\
\qquad 20-30 \mathrm{~mm}^{1}\end{array}$} & $S$ & 100 & $297 \pm 15$ & $11.5 \pm 1.8$ & $20.2 \pm 7.6$ & 3.15 & 2.02 \\
\hline & & & & $\mathrm{B}$ & 31 & $391 \pm 27$ & $11.2 \pm 1.4$ & $39.8 \pm 9.9$ & 1.21 & 1.23 \\
\hline & & & & W & - & - & - & - & - & - \\
\hline & & & $\begin{array}{l}\text { spiral cutting length } \\
30-50 \mathrm{~mm}\end{array}$ & S & 100 & $297 \pm 11$ & $11.4 \pm 1.8$ & $21.7 \pm 7.5$ & 3.14 & 2.08 \\
\hline & & & $\begin{array}{l}\text { spiral cutting length } \\
40-70 \mathrm{~mm}\end{array}$ & S & 63 & $296 \pm 14$ & $11.9 \pm 1.9$ & $22.9 \pm 7.7$ & 2.17 & 1.46 \\
\hline \multirow{5}{*}{$\begin{array}{l}\text { Farmi } \\
\text { CH } 260 \\
\text { HF-2EL }\end{array}$} & \multirow{5}{*}{$\begin{array}{l}70 \text { to } 115 \\
\text { kW }\end{array}$} & \multirow{5}{*}{$260 \mathrm{~mm}$} & \multirow{2}{*}{$\begin{array}{l}\text { PTO-speed } 540 \text { rpm } \\
\text { sharp knives }\end{array}$} & $S$ & 60 & $296 \pm 9$ & $15.9 \pm 2.1$ & $38.7 \pm 10.5$ & 3.58 & 2.32 \\
\hline & & & & $B$ & 45 & $394 \pm 16$ & $15.0 \pm 2.6$ & $75.2 \pm 23.6$ & 3.23 & 3.39 \\
\hline & & & \multirow{2}{*}{$\begin{array}{l}\text { PTO-speed } 1000 \text { rpm } \\
\text { sharp knives }\end{array}$} & $S$ & 65 & $297 \pm 10$ & $16.3 \pm 2.1$ & $43.5 \pm 12.5$ & 4.10 & 2.83 \\
\hline & & & & $\mathrm{B}$ & 48 & $396 \pm 10$ & $15.6 \pm 2.2$ & $37.1 \pm 9,7$ & 3.72 & 2.41 \\
\hline & & & $\begin{array}{l}\text { PT0-speed } 540 \text { rpm } \\
\text { blunt knives }\end{array}$ & $S$ & 65 & $296 \pm 17$ & $15.3 \pm 1.9$ & $73.7 \pm 22.5$ & 3.58 & 3.54 \\
\hline
\end{tabular}

S - Norway spruce

B - European Beech

W - European willow

1 - recommended machine setting for the production of high quality wood chips with the particle size »P31s« according to ISO 17225-4:2021; variation in stem length, stem diameter and stem weight is given as means \pm standard deviation; weight refers to fresh weight at delivery 
trial with the spiral chipper, see Table 1). Before each of the 16 trials, the solid cubic meter volume of each stem (in $\mathrm{m}^{3}$ ) was determined manually. Stem length was measured using a tape measure (Spencers Loggers Tape). Stem diameter was determined on both ends using an electrical caliper (Excaliper, Masser Oy). Individual stem weight (in $\mathrm{kg}$ ) was measured by weighting each stem using a crane scale (DINI ARGEO MCW 1500, AS-Wägetechnik GmbH).

Due to differences in maximum infeed diameter of the three chippers, mean stem diameter differed between the chipping experiments (Table 1). Mean stem diameter was $20.5 \pm 3.6 \mathrm{~cm}$ for the drum chipper, $11.5 \pm 1.8 \mathrm{~cm}$ for the spiral chipper and $15.7 \pm 2.2 \mathrm{~cm}$ for the disc chipper, respectively. This variation might directly influence chipper performance parameters such as fuel consumption or throughput rate (see Section 3.3) but could not be controlled due to a limited availability of raw materials for the chipping experiments. Mean stem length was $297 \pm 13 \mathrm{~cm}$ for Norway spruce and $395 \pm 18 \mathrm{~cm}$ for European beech. No information on length and diameter were determined for crown residues from European willow.

For the main chipping trials, machine settings were adjusted to recommendations of the chipper manufactures for the production of high quality wood chips from beech and spruce stem wood with the particle size class »P31s « according to the revised ISO 172254:2021. These recommendations included the use of sharp knives and small screen mesh sizes $(45 \times 60 \mathrm{~mm})$ for the drum chipper, a spiral cutting length of 20 to $30 \mathrm{~mm}$ for the spiral chipper and the use of sharp knives and a PTO-speed of $540 \mathrm{rpm}$ for the disc chipper (Table 1).

Additional chipping trials could be conducted with varying machine settings such as different screen mesh sizes for the drum chipper, varying spiral cutting lengths for the spiral chipper, different PTO-speeds for the disc chipper and the use of blunt knives for both the drum and disc chipper (Fig. 2, Table 1). In case of the drum chipper, blunt knives derived from chipping of wooden pallets before the experiments. In case of the disc chipper, knives were made blunt artificially by cutting off the knife edge at a thickness of $3 \mathrm{~mm}$. The experimental design of these additional trials could not include all possible combinations of tree species and machine settings due to limited machine availability. Thus, these additional results have to be considered observational in character.

Chippers were powered by a canola oil driven John Deere 6210R tractor. Motor capacity of the tractor was $154 \mathrm{~kW}$. The tractor exceeded energy requirements of all chippers allowing for full utilization of chipping capacities (Table 1). Engine flow and return was channelled through an external fuel tank. During each experiment, canola oil consumption was assessed gravimetrically by constantly measuring the weight of the external fuel tank with a desk scale (KB60.2,
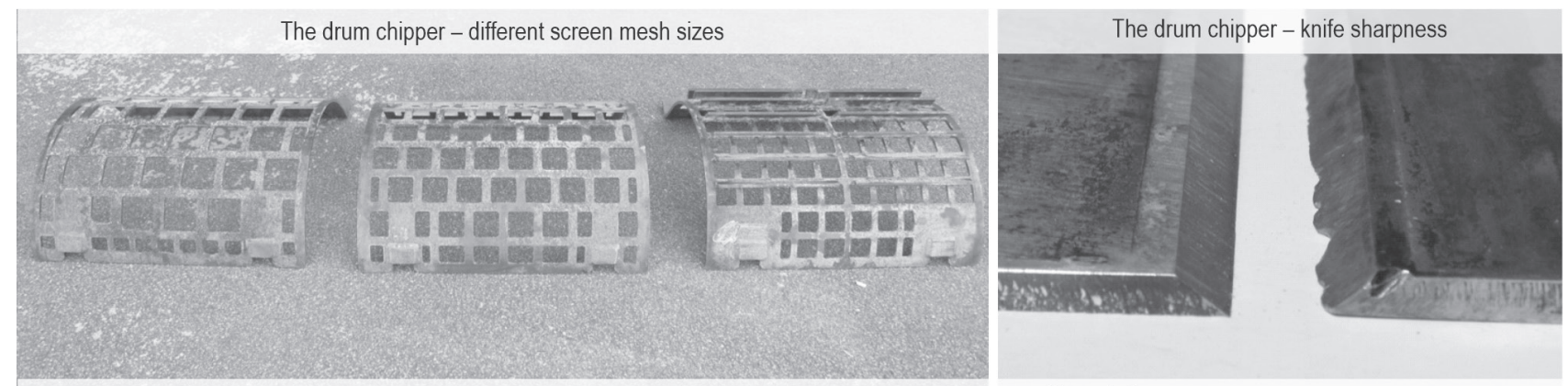

$80 \times 80 \mathrm{~mm}$

$60 \times 60 \mathrm{~mm}$

$45 \times 60 \mathrm{~mm}$

Sharp knives

Blunt knives

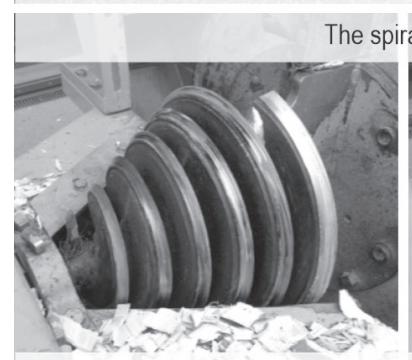

$20-30 \mathrm{~mm}$

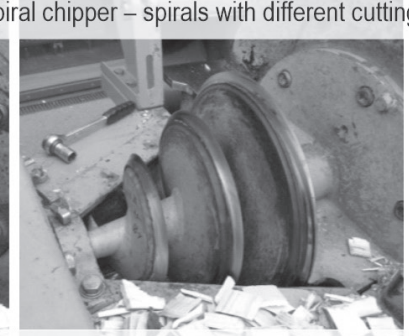

$30-50 \mathrm{~mm}$

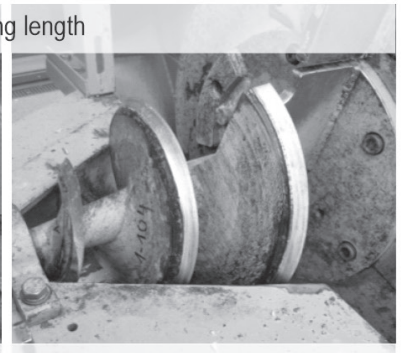

$40-70 \mathrm{~mm}$

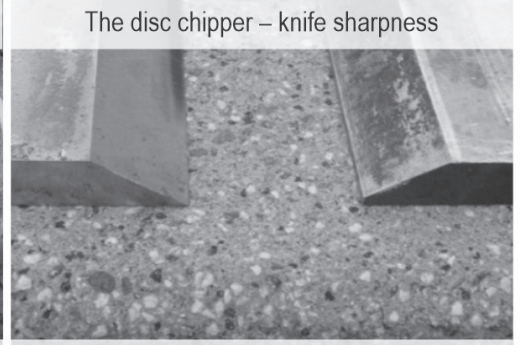

Sharp knives
Artificially blunt knives

Fig. 2 Selected machine variants for chipping trials with drum chipper, the spiral chipper and the disc chipper 
Table 2 Sampling and analyses according to international standards for sold biomass fuels

\begin{tabular}{|l|c|c|}
\hline \multicolumn{1}{|c|}{ Method/Parameter } & Standard & Unit \\
\hline Sampling & ISO 18135 & - \\
\hline Sample preparation & ISO 14780 & - \\
\hline Moisture content & ISO 18134-1 & W-\% (as received) \\
\hline Bulk density & ISO 17828 & $\begin{array}{c}\mathrm{kg} \mathrm{m}^{-3} \text { (as received and } \\
15 \mathrm{~W}-\% \text { moisture content) }\end{array}$ \\
\hline Stowage factor & - & $\mathrm{W}-\%$ (as received) \\
\hline $\begin{array}{l}\text { Particle size } \\
\text { distribution }\end{array}$ & ISO 17827-1 & $\mathrm{W}-\%, \mathrm{~mm}$ \\
\hline
\end{tabular}

Mettler-Toledo). Fuel consumption in kg canola oil was converted to litres of diesel using density and net calorific value of the fuels.

Chipper feeding was done manually. For each chipper, feeding was performed of one single stem at a time. If stem weight was too high for manual feeding (e. g. during experiments with the drum chipper), 6 to 7 stems were loaded on a fork lift using the crane of a forwarder. The fork of the lift was elevated to the level of the chipper desk and stems were pushed into the chipper manually. The simultaneous use of two fork lifts allowed for an almost continuous single stem feeding of the chipper.

For each chipping trial, a total of 2.2 to 4.6 solid $\mathrm{m}^{3}$ of stem wood were processed, resulting in the production of approx. 3.3 to $11.5 \mathrm{~lm}^{3}$ (loose cubic meter) of bulk material. The mean volume of wood chips produced during one trial was $8 \mathrm{~lm}^{3}$. Chips were transferred into an agricultural trailer with a capacity of approx. $9.3 \mathrm{~m}^{3}$ using the respective chipper output systems. If the bulk volume of the wood chips exceeded the trailer capacity in one trial, chipping would be done in two consecutive chipping steps. After chipping, wood chip piles within the container were leveled manually using a rake. Wood chip volume was calculated by measuring the remaining empty volume in the container. Dry weight (odt=oven dried ton) was calculated using fresh weight of the chipped stems and the moisture content of representative wood chip samples (see below). From the data, throughput rate $\left(\mathrm{lm}^{3} \mathrm{~h}^{-1}, \mathrm{odt} \mathrm{h}^{-1}\right)$ and specific energy consumption $\left(\mathrm{l} \mathrm{h}^{-1}\right.$, $\left.1 \mathrm{~lm}^{-3}, 1 \mathrm{odt}^{-1}\right)$ of the chippers were calculated for each trial.

After each chipping trial, a representative wood chip sample of approx. $0.5 \mathrm{~lm}^{3}$ was taken from the respective wood chip batch according to ISO $18135(n=1$ for each trial) by transferring evenly distributed small- er wood chip samples of $0.025 \mathrm{~lm}^{3}(n=20)$ from the trailer into a BigBag. The $0.5 \mathrm{~lm}^{3}$ sample was emptied on a clean floor and homogenised manually using shovels. Representative sub-samples of the $0.5 \mathrm{~lm}^{3}$ batch were taken and analysed for moisture content (ISO 18134-1, $n=3$ ), bulk density (ISO 17828, $n=3$ ) and particle size distribution by horizontal screening (ISO $17827-1, n=1$, see Table 2). Sample reduction was done according to ISO 14780 using a custom build sample divider.

Bulk density was calculated »as received « (a.r.) but also for a moisture content of $15 \mathrm{w}-\%$ (weight- $\%$ ). The "stowage factor «, i. e. the compression behaviour of wood chips, was calculated by relating bulk density of chips with a compression shock (according ISO 17828) to bulk density without such a compression shock. Hole diameters of round hole screens selected for horizontal screening (ISO 17827-1) were $3.15 \mathrm{~mm}$, $8 \mathrm{~mm}, 16 \mathrm{~mm}, 31.5 \mathrm{~mm}, 45 \mathrm{~mm}$ and $63 \mathrm{~mm}$. Classification of wood chips followed the revised ISO standard for graded wood chips (ISO 17225-4:2021) but also the general specifications for solid biofuels according to ISO 17225-1:2021.

In addition to horizontal screening, particle size distribution and particle shape were analysed using a continuously measuring image analysis device (Haver-CPA 4, Haver \& Boecker GmbH, Germany) allowing for highly detailed information on the size and shape of the wood chips (Fig. 3 to 5) (Hartmann et al. 2006, Hinterreiter et al. 2012, Kuptz and Hartmann 2015, Kuptz and Hartmann 2021). The same samples were used for image analysis as for horizontal screening $(n=1)$.

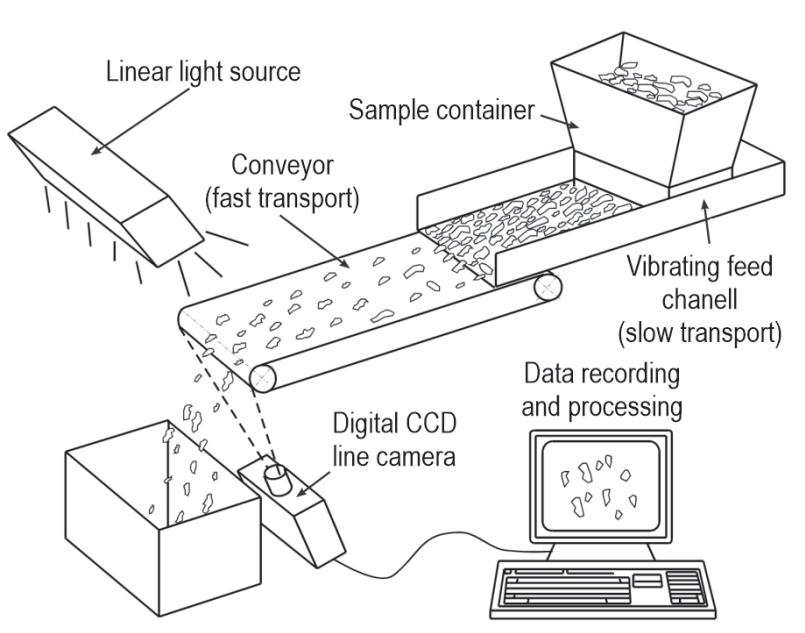

Fig. 3 Schematic drawing of continuously measuring image analysis device (Hartmann et al. 2006, Hinterreiter et al. 2012) 


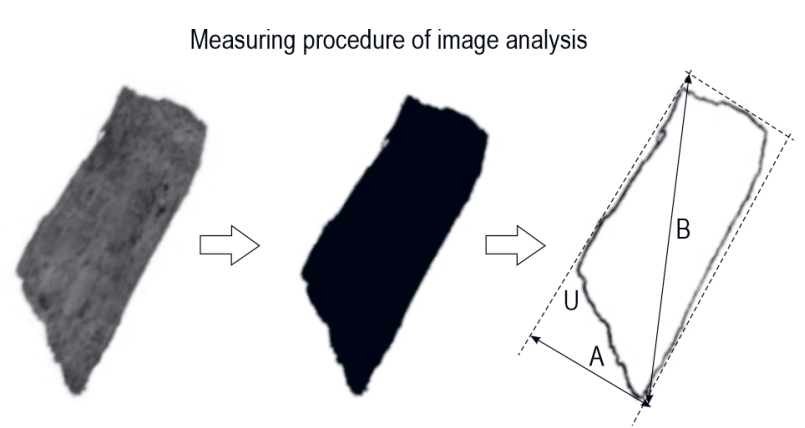

Particle shape factors (PSF)

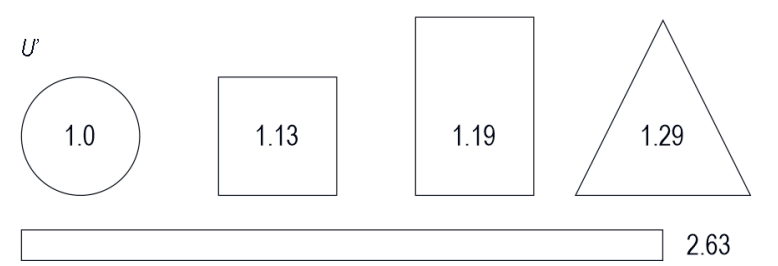

Fig. 4 Measuring principle of image analysis device and examples of particle shape factors (PSF) of particles with equal area

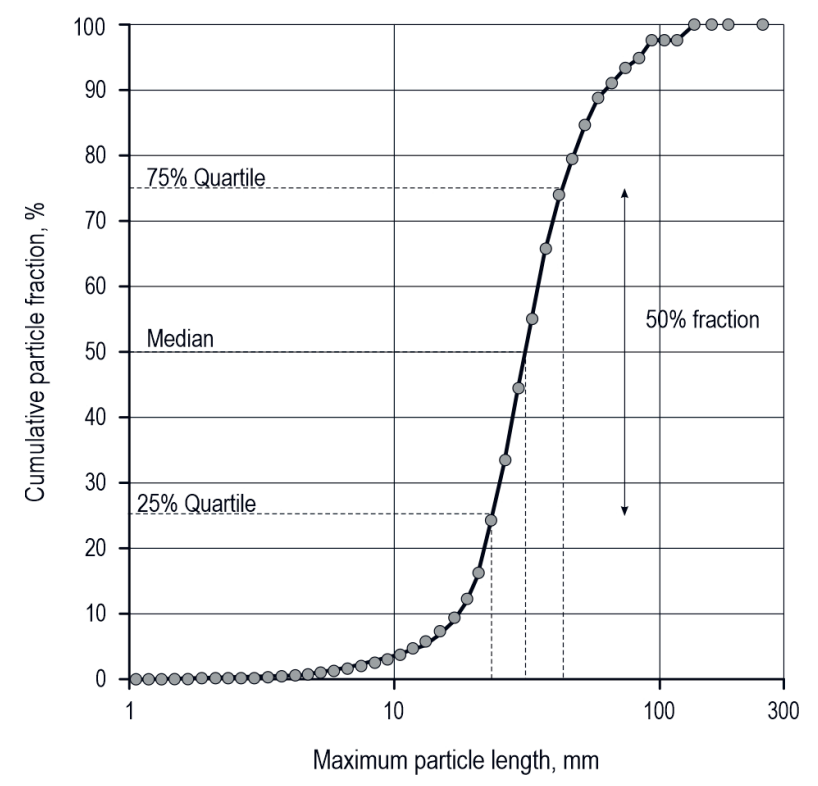

Fig. 5 Example of a particle size distribution measured with a continuously measuring image analysis device

For image analysis, wood chips were spread horizontally by means of a vibrating feed canal and a conveyor belt (Fig. 3). After separation, each individual particle passes a light source opposite of a digital CCD line camera. The camera records 4096 pixels over a width of $400 \mathrm{~mm}$. The resolution per pixel is $98 \mu \mathrm{m}$. From the retention time within the camera scope and the recordings for the varying horizontal expansion, the size of each particle two-dimensional silhouette is recorded and calculated by a computer (Fig. 4).

The image analysis determines particle size as "maximum particle length « (in $\mathrm{mm}$, i.e. arrow »B « in Fig. 4). In contrast, horizontal screening (ISO 17827-1) rather assesses the "particle width « i. e. as the »minimum Feret diameter « (in mm, see arrow »A « in Fig. 4) (Hartmann et al. 2006).

Particle size distribution by image analysis was characterised using the median particle size (Median in $\mathrm{mm}$ ) and the $25 \%$ and $75 \%$ quartiles (Q25 and Q75 in mm, Fig. 5) (Hinterreiter et al. 2012, Kuptz and Hartmann 2015). Particle shape was assessed as the "particle shape factor" (PSF, Fig. 4). The PSF is defined as the quotient of the particle circumference $(\mathrm{U})$ and the circumference of a circle of an equal area $\left(\mathrm{U}^{\prime}\right)$. A high PSF characterises a high deviation from a perfectly round shape having a shape factor of 1 . In the narrow sense, the PSF is a parameter that characterises the degree of a particles approximation towards an ideal sphere. However, with the here applied image analysis, a three-dimensional measurement cannot be performed. Instead of a volume, the calculation is related to the two-dimensional silhouette area (Fig. 4) (Hinterreiter et al. 2012).

Due to the overall small sample sizes ( $n=3$ or $n=1$ ), statistical tests such as ANOVA could only be performed for the fuel parameters »moisture content «, »bulk density« or »stowage factor«. In all other cases (e.g. particle size distribution, throughput rate, energy consumption), the observed trends could not be evaluated statistically but the results were compared to recent literature.

\section{Results and Discussion}

\subsection{Moisture Content and Bulk Density}

Mean moisture content of wood chips was $44.9 \pm 3.4 \mathrm{w}-\%$ for Norway spruce and $41.9 \pm 1.4 \mathrm{w}-\%$ for European beech, respectively (mean \pm standard deviation, Table 3). The lowest moisture contents were measured for wood chips that were produced with the spiral chipper. In many cases, moisture content decreased significantly with decreasing stem diameter during chipping, probably due to some pre-drying of the stems with smaller diameter before the chipping experiments. Consequently, wood chips produced with the spiral chipper (max. infeed-diameter: $170 \mathrm{~mm}$ ) usually had lower moisture contents compared to the drum or disc chipper (max. infeed-diameter: $400 \mathrm{~mm}$ and $260 \mathrm{~mm}$, respectively). This variation might 
Table 3 Mean bulk density, stowage factor and moisture content of wood chips ( $n=3 \pm$ standard deviation) produced with three medium sized chippers

\begin{tabular}{|c|c|c|c|c|c|c|}
\hline \multirow{2}{*}{ Chipper } & \multirow{2}{*}{$\begin{array}{c}\text { Tree } \\
\text { species }\end{array}$} & \multirow{2}{*}{ Machine setting } & \multirow{2}{*}{$\begin{array}{l}\text { Moisture content in } \\
\qquad \text { w-\% }\end{array}$} & \multicolumn{2}{|c|}{ Bulk density } & \multirow{2}{*}{$\begin{array}{c}\text { Stowage factor } \\
\text { in } w-\%\end{array}$} \\
\hline & & & & $\mathrm{kg} \mathrm{m}^{-3}$, a.r. & $\mathrm{kg} \mathrm{m}^{-3}, M=15 \mathrm{w}-\%$ & \\
\hline \multirow{6}{*}{$\begin{array}{l}\text { Heizohack } \\
\text { HM } 8400\end{array}$} & \multirow{4}{*}{ Spruce } & $45 \times 60 \mathrm{~mm}$, sharp knives ${ }^{1}$ & $46.7 \pm 1.0^{\text {ghi }}$ & $271 \pm 2^{f}$ & $170 \pm 1^{d}$ & $9.8 \pm 0.3$ \\
\hline & & $60 \times 60 \mathrm{~mm}$, sharp knives & $44.3 \pm 0.4^{\text {defg }}$ & $260 \pm 1^{\text {de }}$ & $170 \pm 1^{d}$ & $9.6 \pm 0.5$ \\
\hline & & $80 \times 80$ mm, sharp knives & $47.9 \pm 0.3^{i}$ & $270 \pm 2^{f}$ & $166 \pm 1^{\text {cd }}$ & $9.1 \pm 0.3$ \\
\hline & & $80 \times 80 \mathrm{~mm}$, blunt knives & $46.1 \pm 0.9^{\text {fghi }}$ & $269 \pm 4^{\text {ef }}$ & $171 \pm 2^{d}$ & $10.3 \pm 1.8$ \\
\hline & \multirow{2}{*}{ Beech } & $45 \times 60$ mm, sharp knives ${ }^{1}$ & $42.7 \pm 0.3^{\text {cde }}$ & $380 \pm 2^{i}$ & $256 \pm 1^{\text {gh }}$ & $9.7 \pm 0.5$ \\
\hline & & $80 \times 80 \mathrm{~mm}$, sharp knives & $43.5 \pm 0.2^{\text {ddef }}$ & $401 \pm 1^{j}$ & $266 \pm 1^{i}$ & $10.4 \pm 0.5$ \\
\hline \multirow{5}{*}{$\begin{array}{l}\text { Laimet HP } \\
21\end{array}$} & \multirow{3}{*}{ Spruce } & $20-30 \mathrm{~mm}^{1}$ & $37.8 \pm 1.7^{\mathrm{a}}$ & $208 \pm 2^{\mathrm{a}}$ & $152 \pm 1^{\mathrm{a}}$ & $10.6 \pm 0.7$ \\
\hline & & $30-50 \mathrm{~mm}$ & $39.8 \pm 2.3^{\mathrm{ab}}$ & $228 \pm 5^{b}$ & $161 \pm 4^{\mathrm{bc}}$ & $10.2 \pm 0.5$ \\
\hline & & 40-70 mm & $46.3 \pm 1.4^{\text {ghi }}$ & $248 \pm 2^{c}$ & $157 \pm 1^{a b}$ & $10.0 \pm 0.3$ \\
\hline & Beech & $20-30 \mathrm{~mm}^{1}$ & $39.7 \pm 0.1^{\mathrm{ab}}$ & $321 \pm 3^{g}$ & $228 \pm 2^{f}$ & $10.1 \pm 1.1$ \\
\hline & Willow & $20-30 \mathrm{~mm}^{1}$ & $44.9 \pm 0.8^{\text {effh }}$ & $276 \pm 7^{f}$ & $179 \pm 5^{\mathrm{e}}$ & $10.4 \pm 0.6$ \\
\hline \multirow{5}{*}{$\begin{array}{l}\text { Farmi CH } \\
260 \mathrm{HF}-2 \mathrm{EL}\end{array}$} & \multirow{3}{*}{ Spruce } & 540 rpm, sharp knives ${ }^{1}$ & $45.9 \pm 0.6^{\text {fghi }}$ & $254 \pm 3^{\text {cd }}$ & $162 \pm 2^{b c}$ & $9.9 \pm 0.5$ \\
\hline & & 1000 rpm, sharp knives & $47.5 \pm 0.3^{\text {hi }}$ & $273 \pm 2^{f}$ & $169 \pm 1^{d}$ & $9.9 \pm 0.3$ \\
\hline & & 540 rpm, blunt knives ${ }^{1}$ & $47.1 \pm 0.3^{\mathrm{hi}}$ & $257 \pm 1^{\text {cd }}$ & $160 \pm 1^{\mathrm{bc}}$ & $9.9 \pm 0.3$ \\
\hline & \multirow{2}{*}{ Beech } & 540 rpm, sharp knives & $41.4 \pm 0.3^{\mathrm{bc}}$ & $371 \pm 2^{h}$ & $255 \pm 1^{g}$ & $10.0 \pm 0.3$ \\
\hline & & 1000 rpm, sharp knives & $42.0 \pm 0.4^{\text {bcd }}$ & $384 \pm 3^{i}$ & $262 \pm 2^{\text {hi }}$ & $9.4 \pm 0.6$ \\
\hline
\end{tabular}

1 - machine setting recommended by the chipper manufacturer for the production of high quality wood chips with the particle size class P31s according to ISO 17225-4:2021; differing minor characters display significant differences $(p \leq 0.05)$ among mean values calculated by ANOVA with a Tukey post-hoc test

influence processing parameters such as fuel consumption or throughput rate during chipping (see Section 3.3).

Bulk density (a.r. $=$ as received) was significantly higher for beech chips ( 321 to $401 \mathrm{~kg} \mathrm{~m}^{-3}$ ) compared to spruce chips (208 to $276 \mathrm{~kg} \mathrm{~m}^{-3}$, Table 3). The same was true when bulk densities were calculated to an equal moisture content of $15 \mathrm{w}-\%$ (beech: 228 to $266 \mathrm{~kg} \mathrm{~m}^{-3}$, spruce: 152 to $171 \mathrm{~kg} \mathrm{~m}^{-3}$ ). Bulk density from the chipping trials resembled that of wood chips produced at forest production sites (Kuptz and Hartmann 2015). The overall higher bulk density of beech compared to spruce can be related to higher gross densities of the hard wood species (Kaltschmitt et al. 2016).

No clear trend in bulk density (a.r. or at $15 \mathrm{w}-\%$ ) could be observed between different machine settings when the same chipper and the same raw materials were applied (Table 3). This was similar to trials with industrial chippers at forest production sites (Kuptz and Hartmann 2015), showing that bulk density of wood chips might not differ largely due to the use of different machine settings such as different screen mesh sizes or varying knife sharpness. However, during this study, bulk densities of chips produced with the spiral chipper were constantly lower compared to those of the drum or disc chipper. In case of the drum chipper, this effect was statistically significant $(p \leq 0.05$; Table 3). As this was also true for bulk density at a fixed moisture content of $15 \mathrm{w}-\%$, this effect could not be related to different moisture contents of the raw materials. Due to the overall low amount of small particles of wood chips produced with the spiral chipper (see Section 3.2), these chips might incorporate a higher share of free cavities leading to a lower bulk density. A high porosity in bulk fuels might be useful for natural and artificial drying, as it decreases air pressure resistance during ventilation of wood chips (Kristensen et al. 2003, Kuptz and Hartmann 2021, Lenz et al. 2015).

The stowage factor, i. e. the compression behaviour of wood chips, ranged from 9.1 to $10.6 \mathrm{w}-\%$ and was the highest for wood chips produced with the spiral chipper or for wood chips produced with blunt knives (Table 3). Due to the high variance within samples, the 
observed trends were not statistically significant. The slightly higher compression behaviour of wood chips produced with blunt knives compared to sharp knives might be related to a higher share of torn instead of cut particles (Kaltschmitt et al. 2016). Thereby, chips produced with blunt knives resembled hog fuel rather than wood chips (Hinterreiter et al. 2012). The softer surface structure of these chips might be compressed more easily than wood chips with a clear cut surface area. The same might be true for chips produced from crown residues of European willow as these chips incorporate a high share of small twigs and leaves, increasing the overall compressibility of the bulk material. Interestingly, chips produced with the spiral chipper also displayed a higher compression behaviour compared to chips produced with the drum or disc chipper. Chips from the spiral chipper were very homogeneous and had straight cut edges (see Section 3.2). However, these chips were rather flat compared to chips produced with the drum or disc chipper. Thus, they might align more easily during compression compared to chips produced with the other machines leading to the observed higher stowage factors.

\subsection{Particle Size and Particle Form}

Particle size distribution of wood chip samples could be classified as »P31s « in 8 of 16 cases and as P45s in 5 of 16 cases, respectively (see Table 4). The share of fines, i. e. particles $<3.15 \mathrm{~mm}$, never exceeded $10 \mathrm{w}-\%$. Maximum particle length was $142 \mathrm{~mm}$ for wood chips produced from stem wood but exceeded $200 \mathrm{~mm}$ when crown residues from European willow were chipped in the spiral chipper.

A suitable particle size distribution, e. g. »P31s« according to ISO 17225-4:2021, is recommended to minimise problems during fuel feeding (Rackl and Günthner 2016) or during combustion in small-scale boilers (Kaltschmitt et al. 2016, Schön et al. 2019). Using machine settings that were recommended by the chipper manufacturers for the production of high quality fuels usually allowed an allocation to particle size class »P31s« according to ISO 17225-4:2021 when stem wood was used as assortment (Table 4). No differences in particle size distribution could be detected when beech stem wood was processed instead of spruce stem wood, using the same chipper and the same machine settings. Consequently, tree species

Table 4 Particle size distribution according to horizontal screening, maximum particle length and particle size class (ISO 17225-4:2021) of wood chips produced with three medium sized chippers

\begin{tabular}{|c|c|c|c|c|c|c|c|c|c|c|c|}
\hline \multirow[b]{2}{*}{ Chipper } & \multirow[b]{2}{*}{$\begin{array}{c}\text { Tree } \\
\text { species }\end{array}$} & \multirow[b]{2}{*}{ Variation } & \multicolumn{7}{|c|}{ Particle fraction according to horizontal screening in w-\% } & \multirow{2}{*}{$\begin{array}{c}\text { Maximum } \\
\text { particle } \\
\text { length } \\
\text { mm }\end{array}$} & \multirow[b]{2}{*}{$\begin{array}{c}\text { Particle } \\
\text { size } \\
\text { class }\end{array}$} \\
\hline & & & $\begin{array}{c}0-3.15 \\
\mathrm{~mm}\end{array}$ & $\begin{array}{c}3.15-8 \\
\mathrm{~mm}\end{array}$ & $\begin{array}{l}8-6 \\
\mathrm{~mm}\end{array}$ & $\begin{array}{c}16-31.5 \\
\mathrm{~mm}\end{array}$ & $\begin{array}{c}31.5-45 \\
\mathrm{~mm}\end{array}$ & $\begin{array}{c}\text { 45-63 } \\
\mathrm{mm}\end{array}$ & $\begin{array}{l}>63 \\
\mathrm{~mm}\end{array}$ & & \\
\hline \multirow{6}{*}{$\begin{array}{l}\text { Heizohack } \\
\text { HM } 8400\end{array}$} & \multirow{4}{*}{ Spruce } & $45 \times 60 \mathrm{~mm}$, sharp knives ${ }^{1}$ & 7.5 & 18.0 & 48.8 & 21.5 & 4.1 & 0.1 & - & 87 & P31s \\
\hline & & $60 \times 60$ mm, sharp knives & 3.6 & 15.1 & 44.0 & 32.0 & 2.1 & 3.2 & - & 123 & P31s \\
\hline & & $80 \times 80$ mm, sharp knives & 2.0 & 9.2 & 18.7 & 67.0 & 3.1 & - & - & 129 & P31s \\
\hline & & $80 \times 80 \mathrm{~mm}$, blunt knives & 7.4 & 28.1 & 39.0 & 23.3 & 1.4 & 0.9 & - & 126 & P31s \\
\hline & \multirow{2}{*}{ Beech } & $45 \times 60 \mathrm{~mm}$, sharp knives ${ }^{1}$ & 6.8 & 11.4 & 58.8 & 22.2 & 0.8 & - & - & 92 & P31s \\
\hline & & $80 \times 80 \mathrm{~mm}$, sharp knives & 3.7 & 8.9 & 33.1 & 47.9 & 3.6 & 1.6 & 1.3 & 142 & P31s \\
\hline \multirow{5}{*}{$\begin{array}{l}\text { Laimet HP } \\
21\end{array}$} & \multirow{3}{*}{ Spruce } & $20-30 \mathrm{~mm}^{1}$ & 0.8 & 3.0 & 7.4 & 79.0 & 9.9 & - & - & 92 & P31s \\
\hline & & $30-50 \mathrm{~mm}$ & 0.4 & 1.3 & 6.3 & 24.2 & 17.8 & 38.2 & 11.9 & 112 & P63 \\
\hline & & $40-70 \mathrm{~mm}$ & 0.4 & 1.0 & 6.4 & 32.8 & 8.4 & 27.7 & 23.4 & 127 & P63 \\
\hline & Beech & $20-30 \mathrm{~mm}^{1}$ & 1.1 & 2.4 & 12.3 & 74.2 & 9.5 & 0.4 & - & 112 & P31s \\
\hline & Willow & $20-30 \mathrm{~mm}^{1}$ & 2.8 & 12.1 & 43.0 & 34.8 & 2.6 & 4.6 & - & 206 & P31 \\
\hline \multirow{5}{*}{$\begin{array}{l}\text { Farmi CH } \\
260 \mathrm{HF}-2 \mathrm{EL}\end{array}$} & \multirow{3}{*}{ Spruce } & 540 rpm, sharp knives ${ }^{1}$ & 0.9 & 3.6 & 14.7 & 66.6 & 12.3 & 2.0 & - & 117 & P31s \\
\hline & & 1000 rpm, sharp knives & 0.9 & 3.3 & 5.4 & 88.3 & 1.32 & 0.7 & - & 92 & P31s \\
\hline & & 540 rpm, blunt knives ${ }^{1}$ & 8.5 & 23.3 & 53.9 & 13.1 & 1.3 & - & - & 113 & P31s \\
\hline & \multirow{2}{*}{ Beech } & 540 rpm, sharp knives & 1.3 & 3.0 & 9.1 & 80.1 & 6.0 & 0.6 & - & 123 & P31s \\
\hline & & 1000 rpm, sharp knives & 5.4 & 15.2 & 47.6 & 30.7 & 1.1 & - & - & 59 & P31s \\
\hline
\end{tabular}

1 - machine setting recommended by the chipper manufacturer for the production of high quality wood chips with the particle size according to ISO 17225-4:2021; sample size $n=1$ 
(beech, spruce) seemed to be less relevant for particle size distribution during this study, while other parameters such as assortment (stem wood, crown residues), chipper type and chipper setting (e. g. knife sharpness, spiral shape, etc.) might be of higher relevance (see below) (Spinelli et al. 2011).

Conformity with the "s-classes « of the ISO 172254:2021 was not achieved when chipping was done with the spiral chipper using a coarse spiral shape (i. e. a cutting length of $» 30-50 \mathrm{~mm}$ « or » $40-70 \mathrm{~mm} «$ ). This was due to the lack of a distinct main particle fraction $\geq 60 \mathrm{w}-\%$ and due to a high share of overlong particles. The same also applies to chipping of crown residues from European willow where maximum particle length was exceeded (Table 4). In all of these cases, wood chips could be classified as either $» \mathrm{P} 31$ « or $» \mathrm{P} 63$ « according to ISO 17225-4:2021 and ISO 17225-1, and are recommended for industrial use rather than for burning in small-scale boilers.

The three applied chipping spirals of the Laimet HP 21 mainly differ in cut length, leading to larger particles when a coarse chipping spiral is used instead of a smaller sized one. Similar trends could be observed for the cut length of drum or disc chippers in the literature (Facello et al. 2013a, Spinelli and Magagnotti 2012), indicating that this parameter is highly relevant for wood chip particle size and that chipper cut length should be adjusted to the required particle size class.

Chipping of forest residues instead of stem wood often leads to a strong increase of fines and overlong particles due to overall higher shares of leaves and small twigs in fuels (Assirelli et al. 2013, Kuptz and Hartmann 2015, Spinelli and Magagnotti 2012). The same applies here for the observed differences in particle size distribution for European willow chips produced with the spiral chipper compared to wood chips from stem wood. Chipping of forest residues often prevents the classification of wood chips according to ISO 17225-4, thus these fuels have to be considered unsuitable for small-scale combustion. Although recent studies highlighted the improvement of fuel particle size distributions by industrial screening techniques such as drum, star or jigger screens (Kuptz et al. 2019, Nati et al. 2015, Oveisi et al. 2018), these secondary fuel upgrading methods might be less attractive for private users of small-scale boilers due to the additional costs for processing and transport (Eriksson et al. 2013). Consequently, the use of stem wood instead of forest residues is recommended for this user group.

Using larger screen mesh sizes for the drum chipper increased the maximum particle length and shifted the average particle size from $» 8$ to $16 \mathrm{~mm}$ « to $» 16$ to $31.5 \mathrm{~mm}$ « (Table 4$)$. This effect was expected as chip- per screens are mainly used to minimise the share of overlong particles in fuels (Eliasson et al. 2015, Nati et al. 2010). In contrast to previous studies (Kons et al. 2015), clear differences in optimal screen size for the production of wood chips according to the revised ISO 17225-4:2021 could be detected and a particle size class »P31s« could only be produced with the narrow chipper screen.

The share of fine particles $<3.15 \mathrm{~mm}$ strongly increased when chipping was done with blunt instead of sharp knives (drum and disc chipper). Although chips could here still be classified as »P31s« or »P45s«, chipping with blunt knives will usually prevent the possibility of making any classification according to ISO 17225-4:2021 (Kuptz and Hartmann 2015). In accordance with other studies, results indicate that blunt knives lead to breaking and grinding of the fuels instead of cutting of the raw materials (Facello et al. 2013b, Nati et al. 2014, Spinelli et al. 2014). Consequently, the use of sharp knives may be considered mandatory for the production of high quality fuels. Overall, the lowest amount of fines was produced with the spiral chipper (0.4 to $1.1 \mathrm{w}-\%$ for stem wood) probably due to a rather smooth cutting and the absense of any impact crushing compared to a disc or drum chipper.

Particle length distribution and particle shape were additionally determined on the same samples using a continously measuring image analysis device (Fig. 6). In most cases, results on particle length distribution by image analysis closely matched results on particle size distribution by horizontal screening. Median particle length and the overall range of the particle length distribution increased when chipping was done with larger screen mesh sizes (drum chipper) and coarse chipper spirals (spiral chipper) but also when a lower PTO-speed was applied (disc chipper). For the here applied disc chipper, a higher PTO-speed directly increases the chipper rotor speed providing more cuts per running meter of wood fed into the chipper and, thus, leading to overall smaller particles. The lowest share of fines in wood chips was produced by the spiral chipper, even when crown residues from European willow with relevant fractions of small twigs and leaves were applied.

The use of blunt knives both increased (drum chipper) and decreased (disc chipper) the particle length of the main fraction (Fig. 6). In case of the disc chipper, the use of blunt knives also increased the share of fine particles. During chipping with the disc chipper (blunt knives), infeed-rollers stopped regularly due to chipper overcharging (»no-stress « automatic) while the chipper rotor continued working. Thus, more cuts might have occured per running meter of wood, further decreasing the mean particle size and increasing 
the share of fines. Consequently, although the specifications of ISO 17225-4:2021 class »P31s « were met, applying blunt knives for wood chip production with the disc chipper should still be avoided to decrease mechanical stress of the machine (see also Section 3.3).

A high particle shape factor (PSF) indicates a strong deviation of a particle from a perfectly round shape. This deviation might lead to fuel related problems during combustion such as increased bridging in silo outlets (Daugbjerg Jensen et al. 2004, Hinterreiter et al. 2012), malfunction of screw-conveyors and higher decomposition of biomass by microbial activity during outdoor storage due to the increased particle surface area (Pecenka et al. 2018). In the present study, PSF of wood chips were lower compared to samples from forest operations with industrial drum chippers that usually produce wood chips with a PSF between 2 and 3.5 (Kuptz and Hartmann 2015). Thus, results indicate a more homogeneous particle form when wood chips from stem wood are produced with the here applied chippers making these process chains highly suitable for the fuel production of small-scale boilers.

Throughout all experiments, the spiral chipper provided both the lowest and the highest PSF. The most homogeneous particle shape among chippers was produced by the spiral chipper when stem wood was chipped (Fig. 6), while chipping of crown residues of European willow strongly increased PSF, indicating an overall more heterogeneous particle shape due to higher shares of twigs and leaves. PSF also slightly increased when chipping was done with larger screen meshes (drum chipper), wider coil distance (spiral chipper) and with blunt knives (drum and disc chipper). Especially for chipping with blunt knives, particles were broken rather than cut leading to a more heterogeneous particle shape.

Due to the small sample size $(n=1)$ for the analysis of particle size and particle form per chipping trial, no statistical evaluation was possible, and other factors might contribute to the observed trends. Thus, the present results must be considered observational in character. Sampling of the individual wood chip batches after chipping was representative ( $n=20 \mathrm{sub}$ samples per batch, ISO 18135), as were the analysis samples derived from consequent sample reduction according to ISO 14780. Thus, special care was taken to reduce possible sampling errors.

\subsection{Throughput Rate and Fuel Consumption}

Similar to wood chip quality, throughput rate and fuel consumption seemed to be highly dependent on the raw materials and machine settings, while no clear

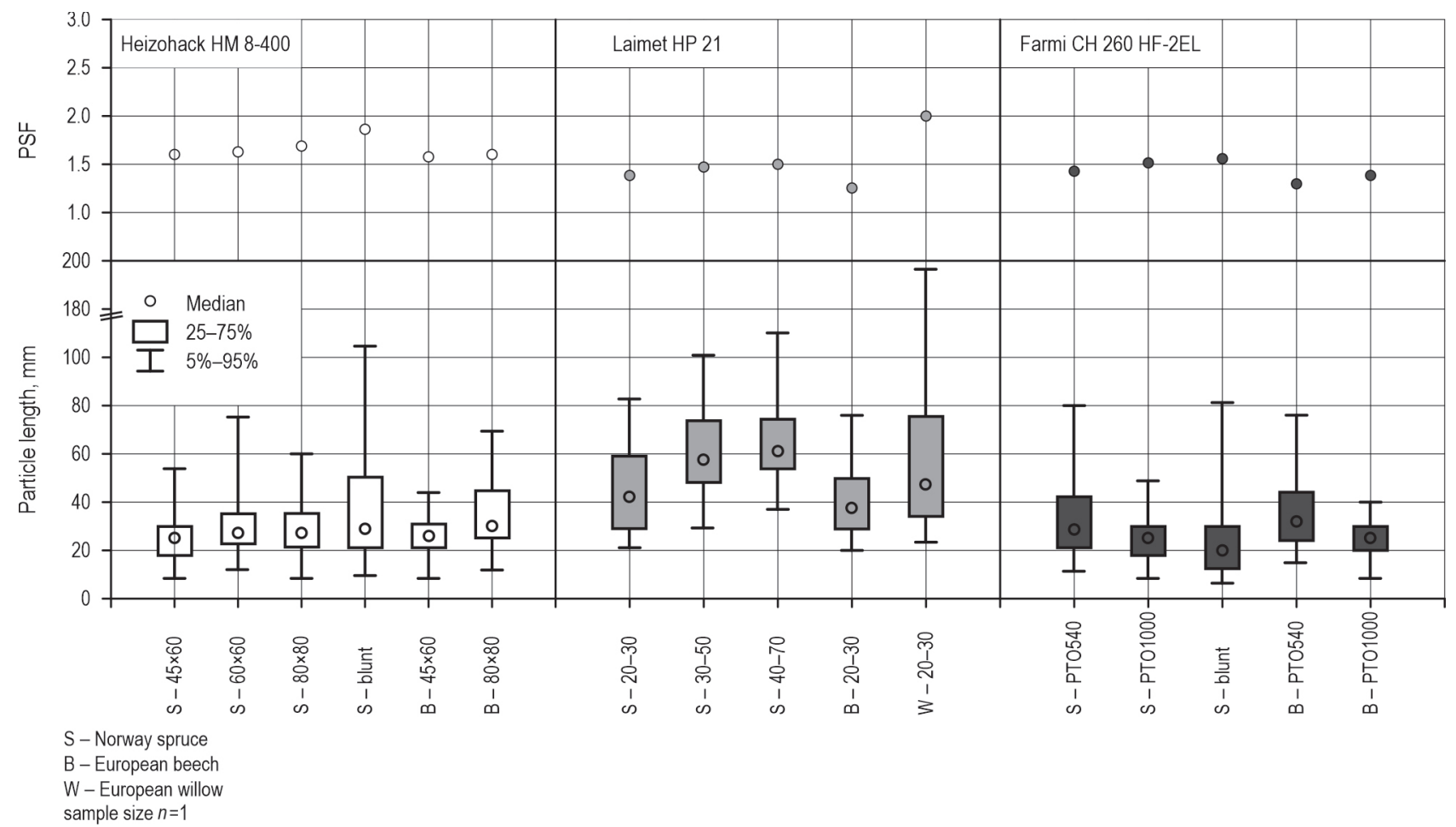

Fig. 6 Particle lengths and particle shave factor (PSF) of wood chips produced with three medium sized chippers, determined by a continuously measuring image analysis 
difference could be observed between chipper types. For this study, both the results on throughput rate and fuel consumption must be considered observational in character as no statistical evaluation could be performed ( $n=1$ per chipping trial). Results can only be interpreted carefully by comparing the observed trends to results from recent literature. Thereby, the study design further limits the interpretation of the results as other controlled or uncontrolled factors during processing (e. g. mean stem diameter of the raw materials, differences in fuel moisture content, single stem chipping vs multiple stem chipping, etc.) might strongly influence chipper performance. These factors remained undetected during these experiments. Consequently, no definite assessment on the overall contribution of each investigated factor (e.g. tree species, assortment, chipper type, chipper setting) could be made from the results.

Throughput rates ranged from 38.5 to $61.8 \mathrm{~lm}^{3} \mathrm{~h}^{-1}$ and from 3.9 to $10.9 \mathrm{odth}^{-1}$, respectively (Table 5). Volume based throughput rate $\left(\mathrm{lm}^{3} \mathrm{~h}^{-1}\right)$ was usually higher during the production of wood chips from spruce compared to beech using the same machine setting. In most cases, the opposite was true when throughput rate was related to mass (odt $\mathrm{h}^{-1}$ ) instead of volume. Regarding different machine settings, throughput rate strongly declined when blunt knives were applied (drum and disc chipper). Using a higher PTO-speed increased throughput rate (disc chipper).

Fuel consumption ranged from 11.9 to $26.41 \mathrm{~h}^{-1}$. Wood chip specific fuel consumption was 0.3 to $0.61 \mathrm{~lm}^{-3}$ and 1.5 to $4.91 \mathrm{odt}^{-1}$, respectively. Thereby, volume based fuel consumption $\left(1 \mathrm{~lm}^{-3}\right)$ increased when chipping was done using narrow screen meshes (drum chipper), narrow coil distance (spiral chipper), a higher PTO-speed (disc chipper) and, most profoundly, when beech was chipped instead of spruce or when chipping was done with blunt knives (disc chipper). In case of different machine settings, the same could also be observed for mass based fuel consumption $\left(\mathrm{lodt}^{-1}\right)$. However, mass based fuel consumption remained largely unchanged or was even slightly decreased when beech was chipped instead of spruce (Table 5).

In recent literature, throughput rate usually decreases and fuel consumption increases when narrow screen sizes, narrow cutting lenghtes and blunt knives are used for chipping (Eliasson et al. 2015, Nati et al. 2014, Spinelli et al. 2014). The same trend was observed during this study. As highlighted in a recent literature review (Bergström and Di Fulvio 2019), the production of fuels with smaller particles requires more energy than the production of fuels with larger particle size.
During this study, this effect was enhanced further for the disc chipper using blunt knives, as this setting frequently led to chipper overcharging (i.e. the »no-stress « automatic was activated), stopping infeed-rollers and, thus, leading to overall longer production times.

Regarding different tree species, higher volume based throughput rates $\left(\mathrm{lm}^{3} \mathrm{~h}^{-1}\right)$ and lower specific fuel consumption $\left(1 \mathrm{~lm}^{-3}\right)$ were observed when spruce was chipped instead of beech, while this effect disappeared or even reversed for mass based calculations (odt h ${ }^{-1}$, 1 odt $\left.^{-1}\right)$. This is likely related to the higher gross density of beech compared to spruce (Kaltschmitt et al. 2016). Thus, production time for the same bulk volume takes longer for beech, whereas in relation to fuel mass, the effect of tree species was rather negligible, as the higher energy density of beech wood compensated for the longer production.

To enhance energy efficiency during chipping, clear recommendations could be drawn from the results: In case of the drum chipper, the use of a large screen mesh size might be recommended, as the larger screen did not negatively affect particle size distribution but led to overall lower fuel consumption, as it was also reported in recent literature (Eliasson et al. 2015, Nati et al. 2014). However, as narrow screens might help to prevent high shares of overlong particles, the use of narrow screens might still be considered useful to guarantee a high fuel quality. In case of the spiral chipper, the use of coarse chipper spirals strongly decreased fuel consumption. However, coarse chipper spirals can only be recommended if chips are produced for larger applications, as particle size distribution prevents the use of these chips in small furnaces. No clear difference could be observed between different PTO-speeds for the disc chipper.

The results of both the disc and the drum chipper strongly indicate that the use of blunt knives leads to a strong decrease in throughput rate and a distinct increase in fuel consumption. This effect was frequently observed in previous studies as blunt knives lead to grinding of the material rather than cutting (Facello et al. 2013b, Nati et al. 2014). Grinding requires more energy than cutting (Bergström and Di Fulvio 2019) resulting in the clear recommendation that the use of blunt knives should be avoided for energy efficient wood chip production. The use of blunt knives might also lead to elevated noise (Poje et al. 2018) and to higher dust emissions due to higher shares of fine particles that might be considered hazardous for the operator's health (Gulci et al. 2018). Therefore, the call for sharp knives is further emphasised.

Overall, results indicate that for the here applied chippers, a high potential for chipper fine-tuning in 
Table 5 Throughput rate and specific fuel consumption of three medium sized chippers during production of wood chips

\begin{tabular}{|c|c|c|c|c|c|c|c|}
\hline \multirow{2}{*}{ Chipper } & \multirow{2}{*}{ Tree species } & \multirow{2}{*}{ Variation } & \multicolumn{2}{|c|}{ Throughput rate } & \multicolumn{3}{|c|}{ Specific fuel consumption } \\
\hline & & & $\operatorname{lm}^{3} h^{-1}$ & odt $h^{-1}$ & $\mathrm{I}^{-1}$ & $1 \mathrm{Im}^{-3}$ & lodt $^{-1}$ \\
\hline \multirow{6}{*}{ Heizohack HM 8400} & \multirow{4}{*}{ Spruce } & $45 \times 60 \mathrm{~mm}$, sharp knives ${ }^{1}$ & 56.0 & 8.4 & 22.9 & 0.41 & 2.72 \\
\hline & & $60 \times 60 \mathrm{~mm}$, sharp knives & 51.4 & 8.3 & 19.9 & 0.39 & 2.40 \\
\hline & & $80 \times 80 \mathrm{~mm}$, sharp knives & 56.6 & 8.4 & 20.4 & 0.36 & 2.43 \\
\hline & & $80 \times 80 \mathrm{~mm}$, blunt knives & 46.0 & 7.3 & 19.5 & 0.42 & 2.67 \\
\hline & \multirow{2}{*}{ Beech } & $45 \times 60 \mathrm{~mm}$, sharp knives ${ }^{1}$ & 43.9 & 9.7 & 26.4 & 0.60 & 2.71 \\
\hline & & $80 \times 80 \mathrm{~mm}$, sharp knives & 51.3 & 10.9 & 25.7 & 0.50 & 2.35 \\
\hline \multirow{5}{*}{ Laimet HP 21} & \multirow{3}{*}{ Spruce } & $20-30 \mathrm{~mm}^{1}$ & 53.6 & 8.1 & 23.6 & 0.44 & 2.93 \\
\hline & & 30-50 mm & 58.9 & 9.6 & 22.0 & 0.37 & 2.29 \\
\hline & & 40-70 mm & 61.8 & 9.1 & 21.3 & 0.34 & 2.34 \\
\hline & Beech & $20-30 \mathrm{~mm}^{1}$ & 38.5 & 8.4 & 23.8 & 0.62 & 2.82 \\
\hline & Willow & $20-30 \mathrm{~mm}^{1}$ & 39.8 & 6.1 & 11.9 & 0.30 & 1.96 \\
\hline \multirow{5}{*}{ Farmi CH 260 HF-2EL } & \multirow{3}{*}{ Spruce } & 540 rpm, sharp knives ${ }^{1}$ & 40.5 & 5.7 & 13.3 & 0.33 & 2.35 \\
\hline & & 1000 rpm, sharp knives & 49.5 & 7.9 & 18.8 & 0.38 & 2.38 \\
\hline & & 540 rpm, blunt knives & 29.8 & 3.9 & 19.0 & 0.64 & 4.88 \\
\hline & \multirow{2}{*}{ Beech } & 540 rpm, sharp knives ${ }^{1}$ & 45.1 & 10.8 & 16.6 & 0.37 & 1.53 \\
\hline & & 1000 rpm, sharp knives & 40.9 & 9.9 & 19.2 & 0.47 & 1.94 \\
\hline
\end{tabular}

$1=$ machine setting recommended by the chipper manufacturer for the production of high quality wood chips with the particle size according to ISO $17225-4$

terms of energy consumption and fuel quality is possible, as it is also seen in the literature (Spinelli et al. 2016). As the optimal chipper settings might also decrease the stress of the chipper rotor and engine, this might also lead to a decrease in costs for chipper maintenance and repair (Spinelli et al. 2019) and to fewer interuptions during the chipping process in the field (Bergström and Di Fulvio 2019)

\section{Conclusions}

The fuel particle size requirements of the revised ISO 17225-4:2021 could be met with all three machines. Each PTO-driven chipper can be recommended for the production of high quality wood chips for small-scale combustion provided that suitable raw material such as stem wood of European beech or Norway spruce is used and proper machine settings (screen mesh size, spiral type, sharp knives) are applied. Only the narrow spiral shape with a cut length of $» 20-40 \mathrm{~mm}$ « can be recommended for wood chip production according to ISO 17225-4:2021 with the Laimet HP 21, whereas the two other spirals (cut length »30-50 $\mathrm{mm}$ « and »40-70 $\mathrm{mm}$ «) were only suitable for the production of larger size wood chips, e. g. for wood chip gasification or for larger CHP or heating plants. To decrease fuel consumption, managing blade wear is considered mandatory. Furthermore, the use of large screen mesh sizes (drum chipper) and coarse chipper spirals (spiral chipper) can only be recommended if none of the requirements concerning any of the three particle size distribution classes for small-scale boilers (i.e. the »s-classes«) in ISO 17225-4:2021 need to be met.

\section{Acknowledgments}

We would like thank our colleagues Albert Maierhofer, Stefan Winter, Peter Turowski, Florian Mergler, Elisabeth Rist, Alexander Marks, Jens Enke, Sebastian Kirner, Georg Huber, Lena Bornschlegel and Peter Emberger of TFZ and of the Bavarian Forest Research Institute (LWF) for their support during this study. Special thanks go to Heizomat Gerätebau-Energiesysteme GmbH, Eusäko Sägewerksmaschinen and Meier Land- $\mathrm{u}$. Forstmaschinen $\mathrm{GmbH}$ for providing us with suitable medium sized wood chipper. The work was funded by the Bavarian State Ministry of Food, Agriculture and Forestry (BayStMELF) under the grant number $» \mathrm{~K} / 10 / 17$ «

\section{References}

Assirelli, A., Civitarese, V., Fanigliulo, R., Pari, L., Pochi, D., Santangelo, E., Spinelli, R., 2013: Effect of piece size and tree 
part on chipper performance. Biomass and Bioenergy 54: 77-82. https://doi.org/10.1016/j.biombioe.2013.03.029

Bergström, D., Di Fulvio, F., 2019: Review of efficiencies in commuting forest fuels. International Journal of Forest Engineering 30(1): 45-55. https://doi.org/10.1080/14942119.201 9.1550314

Daugbjerg Jensen, P., Mattsson, J., Kofman, P., Klausner, A., 2004: Tendency of wood fuels from whole trees, logging residues and roundwood to bridge over openings. Biomass and Bioenergy 26(2): 107-113. https://doi.org/10.1016/S09619534(03)00101-6

Eliasson, L., Hofsten, H. von, Johannesson, T., Spinelli, R., Thierfelder, T., 2015: Effect of sieve size on chipper productivity, fuel consumption and chip size distribution for open drum chippers. Croatian Journal of Forest Engineering 36(1): 11-17

Eriksson, G., Bergström, D., Nordfjell, T., 2013: The state of the art in woody biomass comminution and sorting in Northern Europe. International Journal of Forest Engineering 24(3): 194-215. https://doi.org/10.1080/14942119.2013.85 2391

Facello, A., Cavallo, E., Magagnotti, N., Paletto, G., Spinelli, R., 2013a: The effect of chipper cut length on wood fuel processing performance. Fuel Processing Technology 116: 228233. https://doi.org/10.1016/j.fuproc.2013.07.002

Facello, A., Cavallo, E., Magagnotti, N., Paletto, G., Spinelli, R., 2013b: The effect of knife wear on chip quality and processing cost of chestnut and locust fuel wood. Biomass and Bioenergy 59: 468-476. https://doi.org/10.1016/j.biombioe.2013.07.012

Gulci, S., Akay, A., Spinelli, R., Magagnotti, N., 2018: Assessing the exposure of chipper operators to wood dust in a roadside landing area. Fresenius Environmental Bulletin 27(6): 4132-4138.

Hartmann, H., Böhm, T., Daugbjerg Jensen, P., Temmerman, M., Rabier, F., Golser, M., 2006: Methods for size classification of wood chips. Biomass and Bioenergy 30(11): 944-953. https://doi.org/10.1016/j.biombioe.2006.06.010

Hinterreiter, S., Hartmann, H., Turowski, P., 2012: Method for determining bridging properties of biomass fuels - experimental and model approach. Biomass Conversion and Biorefinery 2(2): 109-121. https://doi.org/10.1007/s13399-0120033-7

International Organization for Standardization (ISO), 2021: Solid biofuels - Fuel specifications and classes - Part 1: General requirements (ISO 17225-1:2021-06). International Organization for Standardization (ISO): Vernier, Geneva, Switzerland, $63 \mathrm{p}$.

International Organization for Standardization (ISO), 2021: Solid biofuels - Fuel specifications and classes - Part 4: Graded wood chips (ISO 17225-4:2021-02). International Organization for Standardization (ISO): Vernier, Geneva, Switzerland, $8 \mathrm{p}$.

International Organization for Standardization (ISO), 2015: Solid biofuels - Determination of moisture content - Oven dry method - Part 1: Total moisture - Reference method (ISO 18134-1:2015-09). International Organization for Standardization (ISO): Vernier, Geneva, Switzerland, 5 p.

International Organization for Standardization (ISO), 2016: Solid biofuels - Determination of bulk density (ISO 17828:2016-05). International Organization for Standardization (ISO): Vernier, Geneva, Switzerland, 18 p.

International Organization for Standardization (ISO), 2016: Solid biofuels - Determination of particle size distribution for uncompressed fuels - Part 1: Oscillating screen method using sieves with apertures of $3,15 \mathrm{~mm}$ and above (ISO 17827-1:2016-10). International Organization for Standardization (ISO): Vernier, Geneva, Switzerland, 20 p.

International Organization for Standardization (ISO), 2017: Solid biofuels - Sample preparation (ISO 14780:2017-04). International Organization for Standardization (ISO): Vernier, Geneva, Switzerland, $22 \mathrm{p}$.

International Organization for Standardization (ISO), 2017: Solid biofuels - Sampling (ISO 18135:2017-08). International Organization for Standardization (ISO): Vernier, Geneva, Switzerland, $73 \mathrm{p}$.

Kaltschmitt, M., Hartmann, H., Hofbauer, H., 2016: Energie aus Biomasse, $3^{\text {rd }}$ ed.; Springer: Berlin, Heidelberg, Germany, $1755 \mathrm{p}$.

Kons, K., Bergström, D., Di Fulvio, F., 2015: Effects of sieve size and assortment on wood fuel quality during chipping operations. International Journal of Forest Engineering 26(2): 114-123. https://doi.org/10.1080/14942119.2015.1069173

Kristensen, E.F., Kofman, P.D., Jensen, P.D., 2003: Counter pressure on ventilation of different types of wood chip and chunkwood. Biomass and Bioenergy 25(4): 399-408. https:// doi.org/10.1016/S0961-9534(03)00031-X

Kuptz, D., Hartmann, H., 2015: The effect of raw material and machine setting on chipping performance and fuel quality - a German case study. International Journal of Forest Engineering 26(1): 60-70. https://doi.org/10.1080/14942119.2 015.1021529

Kuptz, D., Hartmann, H., 2021: Prediction of air pressure resistance during the ventilation of wood chips as a function of multiple physical fuel parameters. Biomass and Bioenergy 145: 105948. https://doi.org/10.1016/j.biombioe.2020.105948

Kuptz, D., Schreiber, K., Schulmeyer, F., Lesche, S., Zeng, T., Ahrens, F., Zelinski, V., Schön, C., Pollex, A., Borchert, H., Lenz, V., Loewen, A., Nelles, M., Hartmann, H., 2019: Evaluation of combined screening and drying steps for the improvement of the fuel quality of forest residue wood chips - results from six case studies. Biomass Conversion and Biorefinery 9(1): 83-98. https://doi.org/10.1007/s13399-01900389-2

Lenz, H., Idler, C., Hartung, E., Pecenka, R., 2015: Open-air storage of fine and coarse wood chips of poplar from short rotation coppice in covered piles. Biomass and Bioenergy 83: 269-277. https://doi.org/10.1016/j.biombioe.2015.09.018 
Nati, C., Spinelli, R., Fabbri, P., 2010: Wood chips size distribution in relation to blade wear and screen use. Biomass and Bioenergy 34(5): 583-587. https://doi.org/10.1016/j.biombioe.2010.01.005

Nati, C., Eliasson, L., Spinelli, R., 2014: Effect of Chipper Type, Biomass Type and Blade Wear on Productivity, Fuel Consumption and Product Quality. Croatian Journal of Forest Engineering 35(1): 1-7

Nati, C., Magagnotti, N., Spinelli, R., 2015: The improvement of hog fuel by removing fines, using a trommel screen. Biomass and Bioenergy 75: 155-160. https://doi.org/10.1016/j. biombioe.2015.02.021

Oveisi, E., Sokhansanj, S., Lau, A., Lim, C.J., Bi, X., Ebadian, M., Preto, F., Mui, C., Gill, R., 2018: In-depot upgrading the quality of fuel chips for a commercial gasification plant. Biomass and Bioenergy 108: 138-145. https://doi.org/10.1016/j. biombioe.2017.10.036

Pecenka, R., Lenz, H., Idler, C., 2018: Influence of the chip format on the development of mass loss, moisture content and chemical composition of poplar chips during storage and drying in open-air piles. Biomass and Bioenergy 116: 140-150. https://doi.org/10.1016/j.biombioe.2018.06.005

Poje, A., Spinelli, R., Magagnotti, N., Mihelić, M., 2018: The effect of feedstock, knife wear and work station on the exposure to noise and vibrations in wood chipping operations. Silva Fennica 52(1): 1-14. https://doi.org/10.14214/sf.7003

Rackl, M., Günthner, W.A., 2016: Experimental investigation on the influence of different grades of wood chips on screw feeding performance. Biomass and Bioenergy 88: 106-115. https://doi.org/10.1016/j.biombioe.2016.03.011

Schön, C., Kuptz, D., Mack, R., Zelinski, V., Loewen, A., Hartmann, H., 2019: Influence of wood chip quality on emission behaviour in small-scale wood chip boilers. Biomass
Conversion and Biorefinery 9(1): 71-82. https://doi. org/10.1007/s13399-017-0249-7

Spinelli, R., Magagnotti, N., 2012: The Effect of Raw Material, Cut Length, and Chip Discharge on the Performance of an Industrial Chipper. Forest Products Journal 62(7-8): 584-589. https://doi.org/10.13073/FPJ-D-12-00083.1

Spinelli, R., Magagnotti, N., Paletto, G., Preti, C., 2011: Determining the impact of some wood characteristics on the performance of a mobile chipper. Silva Fennica 45(1): 85-95. https://doi.org/10.14214/sf.33

Spinelli, R., Glushkov, S., Markov, I., 2014: Managing chipper knife wear to increase chip quality and reduce chipping cost. Biomass and Bioenergy 62: 117-122. https://doi. org/10.1016/j.biombioe.2014.01.007

Spinelli, R., Eliasson, L., Magagnotti, N., 2016: Increasing wood fuel processing efficiency by fine-tuning chipper settings. Fuel Processing Technology 151: 126-130. https://doi. org/10.1016/j.fuproc.2016.05.026

Spinelli, R., Eliasson, L., Magagnotti, N., 2017: Value Retention, Service Life, Use Intensity and Long-Term Productivity of Wood Chippers as Obtained from Contractor Records. Forests 8(12): 503. https://doi.org/10.3390/f8120503

Spinelli, R., Eliasson, L., Magagnotti, N., 2019: Determining the repair and maintenance cost of wood chippers. Biomass and Bioenergy 122: 202-210. https://doi.org/10.1016/j.biombioe.2019.01.024

Zeng, T., Kuptz, D., Schreiber, K., Schön, C., Schulmeyer, F., Zelinski, V., Pollex, A., Borchert, H., Loewen, A., Hartmann, H., Lenz, V., Nelles, M., 2019: Impact of adhering soil and other extraneous impurities on the combustion and emission behavior of forest residues in a small scale combustion appliance. Biomass Conversion and Biorefinery 9(1): 99-116. https://doi.org/10.1007/s13399-018-00368-z
Authors' addresses:

Daniel Kuptz, PhD*

e-mail: daniel.kuptz@tfz.bayern.de

Hans Hartmann, PhD

e-mail: hans.hartmann@tfz.bayern.de

Technology and Support Centre in the Centre of Excellence for Renewable Resources (TFZ)

Solid Biofuels Department

Schulgasse 18

D-94315, Straubing

GERMANY

* Corresponding author 